\title{
Thermal Expansion, Elastic and Magnetic Properties of FeCoNiCu-Based High-Entropy Alloys Using First-Principle Theory
}

\author{
SHUO HUANG, ${ }^{1,6}$ ÁDÁM VIDA, ${ }^{2,3}$ ANITA HECZEL,${ }^{3}$ ERIK HOLMSTRÖM, ${ }^{4}$ \\ and LEVENTE VITOS ${ }^{1,2,5}$ \\ 1.-Applied Materials Physics, Department of Materials Science and Engineering, Royal Institute \\ of Technology, 10044 Stockholm, Sweden. 2.-Institute for Solid State Physics and Optics, Wigner \\ Research Centre for Physics, P.O. Box 49, Budapest 1525, Hungary. 3.-Department of Materials \\ Physics, Eötvös University, Pázmány Péter Sétány 1/A, Budapest 1117, Hungary. 4.-Sandvik \\ Coromant R\&D, 12680 Stockholm, Sweden. 5.-Department of Physics and Astronomy, Division \\ of Materials Theory, Uppsala University, Box 516, 75120 Uppsala, Sweden. 6.-e-mail: \\ shuoh@kth.se
}

The effects of $\mathrm{V}, \mathrm{Cr}$, and $\mathrm{Mn}$ on the magnetic, elastic, and thermal properties of $\mathrm{FeCoNiCu}$ high-entropy alloy are studied by using the exact muffin-tin orbitals method in combination with the coherent potential approximation. The calculated lattice parameters and Curie temperatures in the face-centered-cubic structure are in line with the available experimental and theoretical data. A significant change in the magnetic behavior is revealed when adding equimolar $\mathrm{V}, \mathrm{Cr}$, and $\mathrm{Mn}$ to the host composition. The three independent single-crystal elastic constants are computed using a finite strain technique, and the polycrystalline elasticity parameters including shear modulus, Young's modulus, Pugh ratio, Poisson's ratio, and elastic anisotropy are derived and discussed. The effects of temperature on the structural parameters are determined by making use of the Debye-Grüneisen model. It is found that $\mathrm{FeCoNiCuCr}$ possesses a slightly larger thermal expansion coefficient than do the other alloys considered here.

\section{INTRODUCTION}

During the last decade, high-entropy alloys $(\text { HEAs })^{1,2}$ have attracted significant attention as they open up a vast compositional space for alloy design. Unlike conventional alloys, HEAs generally consist of four or more elements with equal or nearequal molar ratios. The distinct design concept clarifies many important features in these alloys such as high entropy, sluggish diffusion, and severe lattice distortion. ${ }^{3}$ As a consequence, they are more likely to form a simple, yet chemically disordered solid solution rather than a complex intermetallic phase despite containing multiple components, and most of them adopt face-centered-cubic (fcc), bodycentered-cubic (bcc), or hexagonal-close-packed (hcp) crystallographic structures. ${ }^{4}$ A great variety of interesting and useful properties emerge in this new class of alloys including high hardness, ${ }^{5}$ excellent strength and ductility, ${ }^{6}$ outstanding thermal stability, ${ }^{7}$ as well as good resistances to wear, corrosion, and oxidation. ${ }^{8-10}$

Extensive studies have been devoted to design and optimize advanced HEAs with desired properties, ${ }^{11,12}$ and it has been determined that alloying has an important impact on the crystalline structure and the subsequent mechanical performance. ${ }^{13}$ In the widely studied $\mathrm{FeCrCoNiAl}_{x}$ system, for example, the as-cast structure evolves from the initial single fcc phase to a mixture of fcc + bcc duplex phases, and then a single bcc phase with the increase of $\mathrm{Al}$ concentration. ${ }^{14,15}$ In the $\mathrm{FeCrCo}$ $\mathrm{NiNb}_{x}$ system, it was reported that the addition of $\mathrm{Nb}$ promotes the formation of a Laves phase, which brings about the increment in the yield and fracture strength. ${ }^{16}$ Despite the appreciable efforts in experiments, a comprehensive theoretical understanding of the alloying effects on the fundamental physical 
properties is still missing. This may be attributed to the complexity of the problem related to the chemical and magnetic disorder in connection with the multicomponent nature of the HEAs.

In this work, we select the equi-atomic $\mathrm{FeCoNiCu}$ as the base system. This alloy possesses a single fcc solid solution phase, and it exhibits good plastic properties with the tensile strain up to $14 \% .{ }^{17} \mathrm{By}$ using quantum mechanical first-principle methods, we conduct a systematic study of the effects of $\mathrm{V}, \mathrm{Cr}$, and $\mathrm{Mn}$ additions to the base alloy on the structural, magnetic, elastic, and thermal properties.

\section{METHODOLOGY}

The present calculations were based on the density functional theory in combination with the generalized gradient approximation. ${ }^{18}$ The KohnSham equations were solved within the exact muffin-tin orbitals (EMTO) formalism. ${ }^{19}$ The substitutional disorder was taken into account using the coherent potential approximation (CPA). ${ }^{20}$ The paramagnetic state was simulated by the disordered local moment (DLM) model. ${ }^{21}$ The muffin-tin basis set included $s, p, d$, and $f$ orbitals, and the scalarrelativistic approximation and soft-core scheme were adopted. The Green's function was calculated for 16 complex energy points around the valence states. The total energy was computed via the full charge-density technique. ${ }^{19}$ The present EMTO-CPA approach has been applied previously in the ab initio study of the phase stability, magnetic behavior, and mechanical performance for HEAs. ${ }^{22-25}$

The equilibrium volume, total energy, and bulk modulus were extracted from the equation of state described by an exponential Morse-type function ${ }^{26}$ fitted to the ab initio total energies for a series of different volumes. The single-crystal elastic constants were determined according to the volumeconserving orthorhombic and monoclinic deformations, ${ }^{19}$ and the polycrystalline elastic moduli were obtained via the Voigt-Reuss-Hill averaging method. ${ }^{27}$ The temperature variation of structural parameter was derived by making use of the DebyeGrüneisen model. ${ }^{26}$

\section{RESULTS AND DISCUSSION}

\section{Structural Stability and Curie Temperature}

Figure 1a shows the volume-dependent total energies of $\mathrm{FeCoNiCu}$ for fcc, bcc, and hcp structures within ferromagnetic (FM) and paramagnetic (PM) states, respectively. For clarity, all energies are plotted with respect to the equilibrium total energy of FM fcc. It can be seen that within the considered volume range, the fcc structure is energetically favorable over the bcc and hcp structures irrespective of the magnetic state. Extending this study to the $\mathrm{FeCoNiCu} X(X=\mathrm{V}, \mathrm{Cr}$ and $\mathrm{Mn})$ system (Fig. 1b) shows the fcc structure to be the most stable phase among the three close-packed lattices. These theoretical predictions are in agreement with the experimental observation. ${ }^{1,17,28-32}$

In Fig. 2a, we present the calculated lattice parameters for the $\mathrm{FeCoNiCu}$ and $\mathrm{FeCoNiCuX}$ $(X=\mathrm{V}, \mathrm{Cr}$ and $\mathrm{Mn})$ HEAs in fcc phase for both FM and PM states, along with the available experimental values. ${ }^{1,17,30}$ In general, the two sets of data are in good agreement with each other, the average relative deviation between theory and experiment being below $0.7 \%$. At the same time, alloying with $\mathrm{Cr}$ decreases the volume of the $\mathrm{FeCoNiCu}$ host, which is in line with the experimental observation. In contrast, a volume increase is predicted when equimolar $\mathrm{V}$ and $\mathrm{Mn}$ are introduced. This trend may be attributed by the larger atomic radius of $\mathrm{V}$ and $\mathrm{Mn}$ as compared with that of $\mathrm{Cr}^{33}$

Curie temperature $\left(T_{\mathrm{C}}\right)$ is an important magnetic parameter, which can be obtained from Monte-Carlo simulations based on the ab initio magnetic exchange integrals. Alternatively, $T_{\mathrm{C}}$ can be estimated from the mean-field approximation ${ }^{34}$ as $3 k_{\mathrm{B}} T_{\mathrm{C}}=2\left(E_{\mathrm{PM}}-E_{\mathrm{FM}}\right) /(1-c)$, where $k_{\mathrm{B}}$ is the Boltzmann constant, $c$ is the concentration of the nonmagnetic component, and $E_{\mathrm{PM}}$ and $E_{\mathrm{FM}}$ are the equilibrium total energies for the PM and FM states, respectively. Figure $2 \mathrm{~b}$ shows the calculated Curie temperatures for the $\mathrm{FeCoNiCu}$ and $\mathrm{FeCoNi}-$ $\mathrm{CuX}(X=\mathrm{V}, \mathrm{Cr}$ and $\mathrm{Mn})$ HEAs. The present results are in reasonable agreement with the available theoretical and experimental data. ${ }^{30,35}$ We predict that equimolar $\mathrm{V}, \mathrm{Cr}$, and $\mathrm{Mn}$ additions to $\mathrm{FeCo}-$ $\mathrm{NiCu}$ decrease the Curie temperature from $796 \mathrm{~K}$ to $246 \mathrm{~K}, 251 \mathrm{~K}$, and $146 \mathrm{~K}$, respectively.

The magnetic moments for the $\mathrm{FeCoNiCu}$ and FeCoNiCuX $(X=\mathrm{V}, \mathrm{Cr}$ and $\mathrm{Mn})$ HEAs for the fcc structure at the corresponding equilibrium volumes are summarized in Table I. According to the present findings, in the FM state, the total magnetic moment per atom for $\mathrm{FeCoNiCu}$ is $1.23 \mu_{\mathrm{B}}$, and it decreases to $0.64 \mu_{\mathrm{B}}, 0.55 \mu_{\mathrm{B}}$, and $0.23 \mu_{\mathrm{B}}$ when adding equimolar $\mathrm{V}, \mathrm{Cr}$, and $\mathrm{Mn}$, respectively. This trend is attributed to the magnetic moment of the additional alloying elements, which are antiparallel with that of the $\mathrm{Fe}-\mathrm{Co}-\mathrm{Ni}$ matrix. The changes in the magnetic moments correlate nicely with the trends obtained for the magnetic transition temperature, and the appearance of the $\mathrm{V} / \mathrm{Cr} / \mathrm{Mn}$-matrix antiferromagnetic coupling explains the substantial drop in the Curie temperature as compared with the $\mathrm{FeCoNiCu}$ alloy.

\section{Single-Crystal Elastic Constants}

The elastic properties provide information of the behavior of solids under applied stress conditions. In cubic lattice, there are three independent elastic constants: $C_{11}, C_{12}$, and $C_{44}$. The theoretical singlecrystal elastic constants for the $\mathrm{FeCoNiCu}$ and $\mathrm{FeCoNiCu} X(X=\mathrm{V}, \mathrm{Cr}$, and $\mathrm{Mn})$ HEAs at both FM and PM states are listed in Table II. 

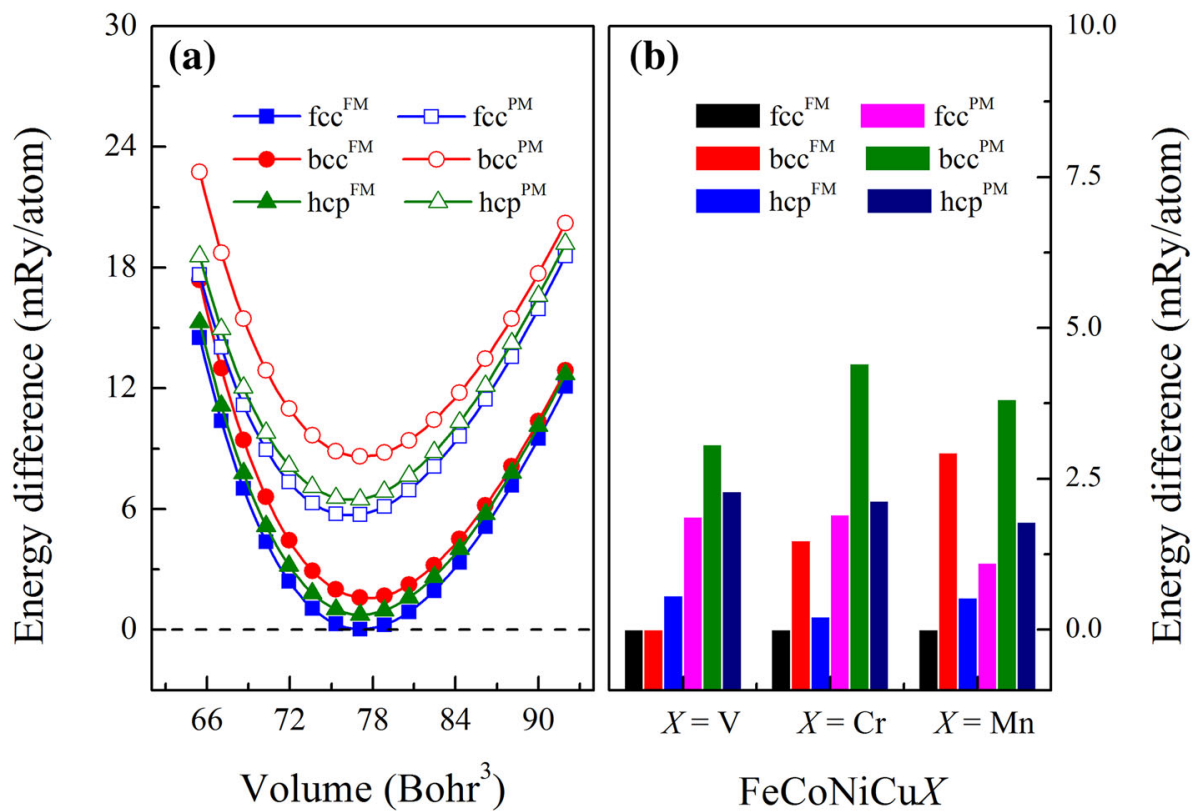

Fig. 1. (a) Total energies for the FeCoNiCu HEA as a function of volume. Results are shown for the fcc, bcc, and hcp structures and for both ferromagnetic (FM) and paramagnetic (PM) states. (b) Equilibrium total energies for the FeCoNiCuX $(X=\mathrm{V}, \mathrm{Cr}$, and $\mathrm{Mn}) \mathrm{HEAs}$. All energies are plotted with respect to the equilibrium total energy corresponding to the FM fcc alloys.

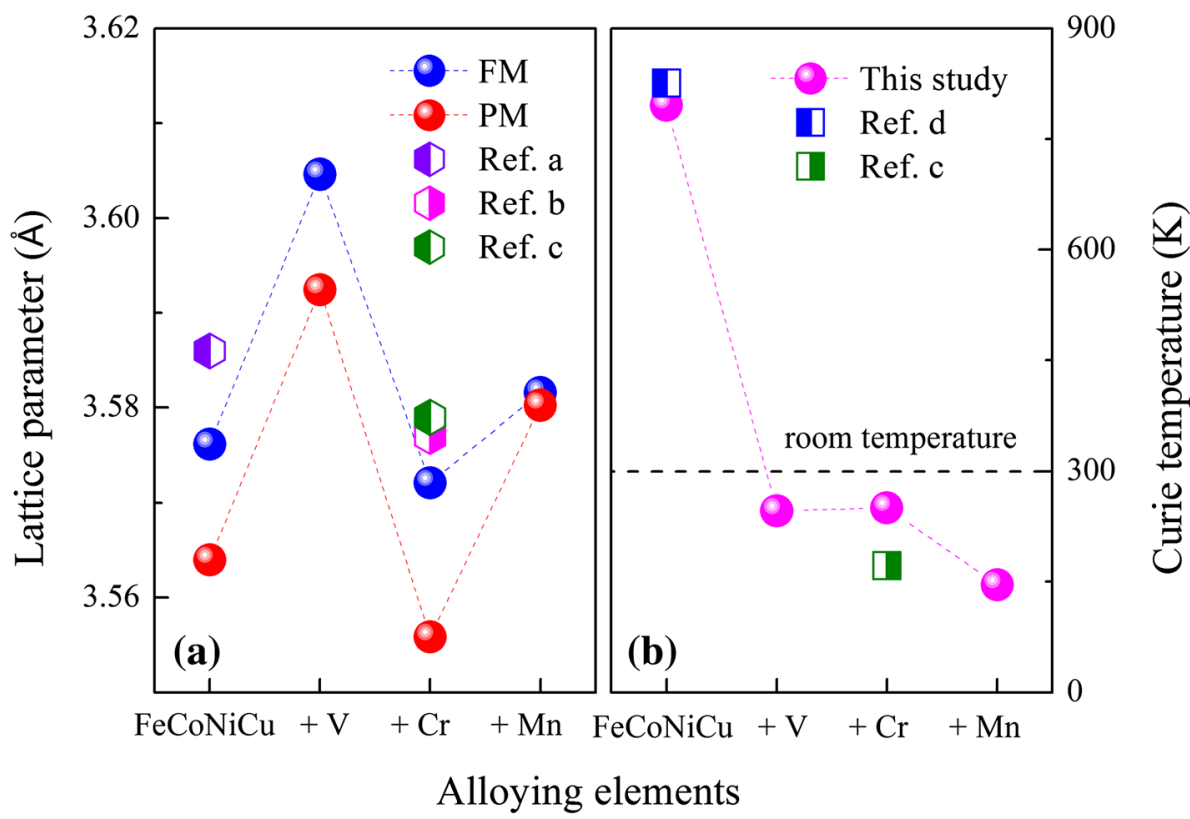

Fig. 2. (a) Theoretical lattice parameters for the FeCoNiCu and FeCoNiCuX ( $X=\mathrm{V}, \mathrm{Cr}$, and Mn) HEAs for the fcc structure and for both ferromagnetic (FM) and paramagnetic (PM) states. (b) Curie temperatures for fcc FeCoNiCu and FeCoNiCuX $(X=\mathrm{V}, \mathrm{Cr}$, and $\mathrm{Mn}) \mathrm{HEAs}$ estimated from the mean field approximation. The quoted experimental and theoretical data are Ref. $a^{17}$ Ref. $b^{1}$ Ref. $c^{30}$ and Ref. $d^{35}$.

The requirement of mechanical stability in a cubic lattice leads to the following restrictions: $C_{11}>0, C_{44}>0, C_{11}-C_{12}>0$, and $C_{11}+2 C_{12}>$ $0 .^{36}$ It is obvious that the calculated elastic constants for all alloys satisfy these mechanical stability conditions. Meanwhile, the tetragonal elastic constant $C^{\prime}$ decreases in both FM and PM states when adding equimolar $\mathrm{V}$ to $\mathrm{FeCoNiCu}$, indicating $\mathrm{V}$ decreases the mechanical stability of the fcc phase. On the other hand, this trend is in line with the expectation based on the equilibrium total energies, namely, that the energy for the FM bcc state is very close to that of the FM fcc state as shown in Fig. 1b. 
Table I. Theoretical total and partial magnetic moments (units of $\mu_{B}$ per atom) for Ferromagnetic fcc FeCoNiCu and FeCoNiCuX (X = V, Cr and Mn) HEAs

\begin{tabular}{|c|c|c|c|c|c|c|}
\hline & $\mathbf{F e}$ & Co & $\mathbf{N i}$ & $\mathbf{C u}$ & $\boldsymbol{X}$ & Total \\
\hline $\mathrm{FeCoNiCu}$ & 2.67 & 1.64 & 0.57 & 0.05 & - & 1.23 \\
\hline$X=\mathrm{V}$ & 2.31 & 1.22 & 0.26 & 0.01 & -0.57 & 0.64 \\
\hline$X=\mathrm{Cr}$ & 2.33 & 1.26 & 0.27 & 0.01 & -1.13 & 0.55 \\
\hline$X=\mathrm{Mn}$ & 2.44 & 1.28 & 0.19 & -0.02 & -2.75 & 0.23 \\
\hline
\end{tabular}

Table II. Theoretical single-crystal elastic constants $\left(C_{11}, C_{12}, C_{44}\right.$, and $C^{\prime}=\left(C_{11}-C_{12}\right) / 2$, in units of GPa), Cauchy pressure $\left(P_{C}=C_{12}-C_{44}\right.$, in units of GPa), polycrystalline elastic modulus (B, $G$, and $Y$, in units of GPa $)$, Poisson's ratio $(v)$, pugh ratio $(B / G)$, zener anisotropy ratio $\left(A_{\mathrm{Z}}\right)$, the elastic anisotropy $\left(A_{\mathrm{VR}}\right)$, density $(\rho$, in units of $\left.\mathrm{g} / \mathrm{cm}^{3}\right)$, longitudinal, transverse and average sound velocities $\left(v_{\mathrm{L}}, v_{\mathrm{T}}\right.$, and $v_{\mathrm{m}}$, in units of $\left.\mathrm{m} / \mathrm{s}\right)$, and Debye Temperature $\left(\theta_{\mathrm{D}}\right.$, in units of $\left.\mathrm{K}\right)$ for the FeCoNiCu and FeCoNiCuX $(X=\mathrm{V}$, Cr and $\mathrm{Mn}) \mathrm{HEAs}$ for the FCC structure and for the ferromagnetic (FM) and paramagnetic (PM) states

\begin{tabular}{|c|c|c|c|c|c|c|c|c|}
\hline & \multicolumn{4}{|c|}{ FM } & \multicolumn{4}{|c|}{ PM } \\
\hline & FeCoNiCu & $\underline{X}=\mathbf{V}$ & $X=\mathbf{C r}$ & $\underline{X=\mathbf{M n}}$ & FeCoNiCu & $\underline{X}=\mathbf{V}$ & $X=\mathbf{C r}$ & $X=\mathbf{M n}$ \\
\hline$C_{11}$ & 211.9 & 196.3 & 209.2 & 189.8 & 213.1 & 207.2 & 223.7 & 187.1 \\
\hline$C_{12}$ & 157.8 & 158.2 & 149.6 & 123.8 & 147.7 & 158.0 & 155.3 & 122.8 \\
\hline$C_{44}$ & 126.9 & 124.1 & 142.2 & 139.2 & 138.2 & 132.8 & 151.3 & 139.3 \\
\hline$C^{\prime}$ & 27.0 & 19.1 & 29.8 & 33.0 & 32.7 & 24.6 & 34.2 & 32.2 \\
\hline$P_{\mathrm{C}}$ & 30.8 & 34.1 & 7.4 & -15.4 & 9.5 & 25.2 & 4.0 & -16.5 \\
\hline$B$ & 175.8 & 170.9 & 169.5 & 145.8 & 169.5 & 174.4 & 178.1 & 144.2 \\
\hline$G$ & 69.1 & 60.4 & 77.0 & 78.8 & 78.2 & 68.8 & 84.1 & 78.1 \\
\hline$Y$ & 183.3 & 162.1 & 200.6 & 200.2 & 203.3 & 182.5 & 218.1 & 198.4 \\
\hline$v$ & 0.326 & 0.342 & 0.303 & 0.271 & 0.300 & 0.326 & 0.296 & 0.271 \\
\hline$B / G$ & 2.54 & 2.83 & 2.2 & 1.85 & 2.17 & 2.53 & 2.12 & 1.85 \\
\hline$A_{\mathrm{Z}}$ & 4.7 & 6.5 & 4.8 & 4.2 & 4.2 & 5.4 & 4.4 & 4.3 \\
\hline$A_{\mathrm{VR}}$ & 0.26 & 0.36 & 0.26 & 0.23 & 0.23 & 0.30 & 0.24 & 0.24 \\
\hline$\rho$ & 8.605 & 8.168 & 8.423 & 8.442 & 8.694 & 8.251 & 8.539 & 8.451 \\
\hline$v_{\mathrm{L}}$ & 5580 & 5548 & 5684 & 5451 & 5611 & 5680 & 5830 & 5420 \\
\hline$v_{\mathrm{T}}$ & 2834 & 2720 & 3023 & 3055 & 2999 & 2888 & 3139 & 3383 \\
\hline$v_{\mathrm{m}}$ & 3176 & 3054 & 3378 & 3400 & 3350 & 3237 & 3504 & 3383 \\
\hline$\theta_{\mathrm{D}}$ & 420 & 400 & 447 & 449 & 444 & 426 & 466 & 447 \\
\hline
\end{tabular}

The three cubic elastic constants for FM (PM) FeCoNiCu are $C_{11}=211.9$ (213.1) $\mathrm{GPa}, C_{12}=157.8$ (147.7) $\mathrm{GPa}$, and $C_{44}=126.9$ (138.2) $\mathrm{GPa}$, which yield 30.8 (9.5) GPa for the Cauchy pressure. We notice that FM (PM) FeCoNiCuMn has a Cauchy pressure of $-15.4(-16.5) \mathrm{GPa}$. In general, negative Cauchy pressure has been associated with the covalent nature of the metallic bond and is characteristic to brittle alloys. ${ }^{37}$ Because of the change of the Cauchy pressure upon equimolar doping, we may conclude that the addition of Mn makes the FeCoNiCu especially brittle. In contrast, V improves the ductility of the host alloy.

\section{Polycrystalline Elastic Moduli}

It is known that shear modulus $G$ represents the resistance to reversible deformations upon shear stress and that Young's modulus $Y$ is defined as the ratio of the tensile stress to the corresponding tensile strain. ${ }^{38}$ As indicated in Table II, we find a nearly linear relationship between $G$ and $Y$ for all alloys considered here. Such a trend is also revealed in many pure metals, as well as in conventional alloys and bulk metallic glasses. ${ }^{39,40}$ Moreover, the FeCoNiCuV possesses the lowest $G$ and $Y$ at both FM and PM states, which indicates that V decreases the stiffness of the host alloy.

We recall that the $B / G$ ratio has often been used to describe the ductile/brittle behavior of materials. According to the Pugh criterion, ${ }^{41}$ a high $B / G$ ratio indicates a tendency for ductility, whereas a small one for brittleness with the critical value around 1.75. From Table II, we find that the FeCoNiCuMn possesses negative Cauchy pressure but with $B / G$ ratio larger than 1.75 . The reason for the slight "inconsistency" between the two empirical predictions for ductility based on Pugh ration and Cauchy pressure is the relative large elastic anisotropy, which results in great uncertainty in the predicted 
shear modulus. ${ }^{42}$ Nevertheless, there is a clear correlation between the two ductility indicators as shown in Table II.

The Debye temperature is an important parameter closely related to a large series of physical properties such as phonon free energy, specific heat, and melting temperature. Here the Debye temperature is estimated using the ab initio data obtained for the elastic constants. ${ }^{19}$ The calculated sound velocity and Debye temperature as well as the density for the $\mathrm{FeCoNiCu}$ and $\mathrm{FeCoNiCu} X(X=\mathrm{V}$, $\mathrm{Cr}$ and $\mathrm{Mn}$ ) HEAs are listed in Table II. We notice that the alloying effect on the Debye temperature is similar to that of shear modulus, indicating that harder material exhibits a higher Debye temperature. Unfortunately, we could not find any published experimental data on the Debye temperature of the present HEAs. Hence the theoretical results may provide guidance for further experimental works.

\section{Thermal Expansion Coefficient}

To compare our results with experiments or to predict the thermal properties of the present FeCoNiCu-based HEAs, we evaluate the thermal expansion coefficient (TEC) using the DebyeGrüneisen model in combination with the present theoretical Debye temperatures. ${ }^{26}$ The TEC is related to anharmonic effects, which are responsible for the change of lattice's volume with temperature. The computed total energy as a function of volume in the static approximation is carried out to determine the structural parameters at ground state and then to derive the macroscopic properties as a function of temperature.

The variations of TEC with temperature for the $\mathrm{FeCoNiCu}$ and $\mathrm{FeCoNiCuX}(X=\mathrm{V}, \mathrm{Cr}$ and $\mathrm{Mn})$ HEAs are presented in Fig. 3. It is shown that for all alloys considered here, the TEC increases rapidly at low temperatures and gradually approaches a linear behavior at high temperatures. We find that the TEC of $\mathrm{FeCoNiCu}$ at $300 \mathrm{~K}$ is around $12.2-$ $12.6 \times 10^{-6} \mathrm{~K}^{-1}$, which is close to that of the other HEAs, e.g., $\sim 14 \times 10^{-6} \mathrm{~K}^{-1}$ for $\mathrm{FeCoNiCr}$ and $\sim 15 \times 10^{-6} \mathrm{~K}^{-1}$ for $\mathrm{FeCoNiCrMn} .{ }^{43,44}$ In addition, the TEC for $\mathrm{FeCoNiCu}, \mathrm{FeCoNiCuV}$, and $\mathrm{FeCoNiC}-$ $\mathrm{uMn}$ are similar, whereas that of $\mathrm{FeCoNiCuCr}$ is slightly higher. It is interesting to notice that austenitic stainless steels have similar thermal expansion coefficients as $\mathrm{FeCoNiCuCr}$. For instance, the average room-temperature TEC for $\mathrm{Fe}_{0.70} \mathrm{Cr}_{0.15} \mathrm{Ni}_{0.15}$ was reported to be $17.3 \times 10^{-6}$ $\mathrm{K}^{-1}{ }^{45}$ The present $\mathrm{Cr}$-free alloys have TEC close to ferritic steels instead. Our theoretical predictions for the TEC may be considered to be the first attempt to predict the thermal properties of these HEAs and to provide information for further studies on similar HEAs.

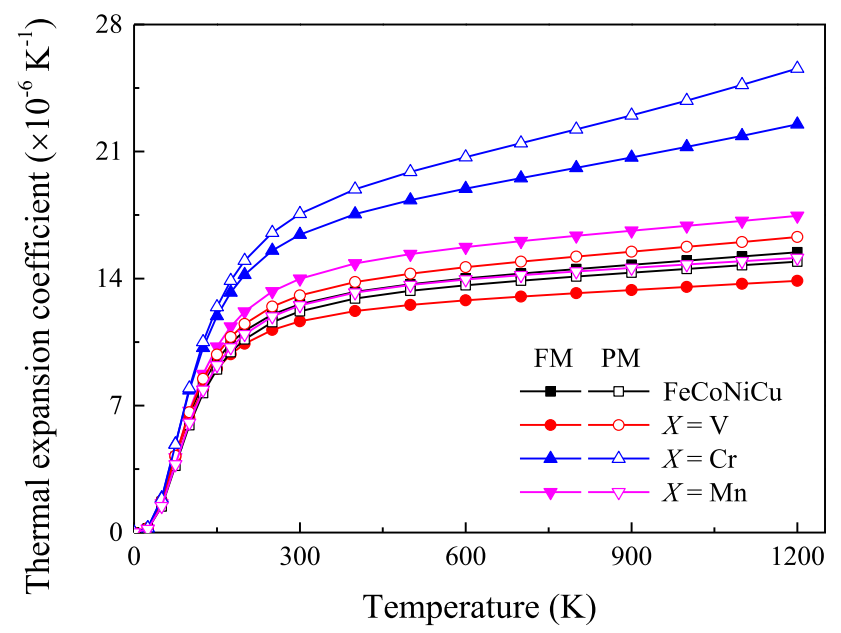

Fig. 3. Thermal expansion coefficient for the FeCoNiCu and FeCoNiCuX $(X=\mathrm{V}, \mathrm{Cr}$, and $\mathrm{Mn})$ HEAs for the fcc structure and for both ferromagnetic (FM) and paramagnetic (PM) states.

\section{CONCLUSION}

First-principle theory has been employed to investigate the magnetic, elastic, and thermal properties of $\mathrm{FeCoNiCu}$ and $\mathrm{FeCoNiCuX}(X=\mathrm{V}, \mathrm{Cr}$ and Mn) HEAs. The present ab initio calculations confirm the stability of the fcc structure relative to the other two close-packed lattices (hcp and bcc) for all alloys considered here. The calculated lattice parameters for the fcc phase are in good agreement with the available experimental data. The Curie temperature estimated from the mean field approximation decreases from $796 \mathrm{~K}$ to $246 \mathrm{~K}, 251 \mathrm{~K}$, and $146 \mathrm{~K}$ when adding equimolar $\mathrm{V}, \mathrm{Cr}$, and $\mathrm{Mn}$ to the $\mathrm{FeCoNiCu}$ host, respectively. The magnetic moments for these alloys are analyzed to understand the fundamental characteristics of the magnetic phase transitions. The effects of the alloying element on the mechanical performance are discussed through the single-crystal and polycrystalline elastic modulus by making use of a series of phenomenological models. The thermal expansion coefficients of these alloys in the $0-1200 \mathrm{~K}$ temperature range are determined from the DebyeGrüneisen model. These alloys show similar thermal expansion behavior and have values of 11.6$17.6 \times 10^{-6} \mathrm{~K}^{-1}$ at room temperature. The present theoretical predictions can serve as a guide for future work on $\mathrm{FeCoNiCu}$-based HEAs.

\section{ACKNOWLEDGEMENTS}

This work was supported by the Swedish Research Council, the Swedish Foundation for Strategic Research, the Swedish Foundation for International Cooperation in Research and Higher Education, the Carl Tryggers Foundation, the 
Sweden's Innovation Agency (VINNOVA Grant No. 2014-03374), the China Scholarship Council, and the Hungarian Scientific Research Fund (OTKA 109570). We acknowledge the Swedish National Supercomputer Centre in Linköping for computer resources.

\section{OPEN ACCESS}

This article is distributed under the terms of the Creative Commons Attribution 4.0 International License (http://creativecommons.org/licenses/by/4.0/ ), which permits unrestricted use, distribution, and reproduction in any medium, provided you give appropriate credit to the original author(s) and the source, provide a link to the Creative Commons license, and indicate if changes were made.

\section{REFERENCES}

1. J.W. Yeh, S.K. Chen, S.J. Lin, J.Y. Gan, T.S. Chin, T.T. Shun, C.H. Tsau, and S.Y. Chang, Adv. Eng. Mater. 6, 299 (2004).

2. B. Cantor, I.T.H. Chang, P. Knight, and A.J.B. Vincent, Mater. Sci. Eng. A 375-377, 213 (2004).

3. J.W. Yeh, JOM 65, 1759 (2013).

4. M.C. Gao, J.W. Yeh, P.K. Liaw, and Y. Zhang, High-Entropy Alloys: Fundamentals and Applications (Switzerland: Springer, 2016).

5. C.J. Tong, M.R. Chen, J.W. Yeh, S.J. Lin, S.K. Chen, T.T. Shun, and S.Y. Chang, Metall. Mater. Trans. A 36, 1263 (2005).

6. C.Y. Hsu, C.C. Juan, W.R. Wang, T.S. Sheu, J.W. Yeh, and S.K. Chen, Mater. Sci. Eng. A 528, 3581 (2011).

7. M.H. Tsai, C.W. Wang, C.W. Tsai, W.J. Shen, J.W. Yeh, J.Y. Gan, and W.W. Wu, J. Electrochem. Soc. 158, H1161 (2011).

8. Y.L. Chou, Y.C. Wang, J.W. Yeh, and H.C. Shih, Corros. Sci. 52, 3481 (2010).

9. Y.F. Kao, T.D. Lee, S.K. Chen, and Y.S. Chang, Corros. Sci. 52, 1026 (2010).

10. M.H. Chuang, M.H. Tsai, W.R. Wang, S.J. Lin, and J.W. Yeh, Acta Mater. 59, 6308 (2011).

11. B. Gludovatz, A. Hohenwarter, D. Catoor, E.H. Chang, E.P. George, and R.O. Ritchie, Science 345, 1153 (2014).

12. Z. Li, K.G. Pradeep, Y. Deng, D. Raabe, and C.C. Tasan, Nature 534, 227 (2016).

13. Y. Zhang, T.T. Zuo, Z. Tang, M.C. Gao, K.A. Dahmen, P.K. Liaw, and Z.P. Lu, Prog. Mater. Sci. 61, 1 (2014).

14. Y.F. Kao, T.J. Chen, S.K. Chen, and J.W. Yeh, J. Alloys Compd. 488, 57 (2009).

15. H.P. Chou, Y.S. Chang, S.K. Chen, and J.W. Yeh, Mater. Sci. Eng. B 163, 184 (2009).

16. W.H. Liu, J.Y. He, H.L. Huang, H. Wang, Z.P. Lu, and C.T. Liu, Intermetallics 60, 1 (2015).

17. L. Liu, J.B. Zhu, C. Zhang, J.C. Li, and Q. Jiang, Mater. Sci. Eng. A 548, 64 (2012).

18. J.P. Perdew, K. Burke, and M. Ernzerhof, Phys. Rev. Lett. 77, 3865 (1996).
19. L. Vitos, Computational Quantum Mechanics for Materials Engineers (London: Springer, 2007).

20. P. Soven, Phys. Rev. 156, 809 (1967).

21. B.L. Györffy, A.J. Pindor, J. Staunton, G.M. Stocks, and H. Winter, J. Phys. F: Met. Phys. 15, 1337 (1985).

22. S. Huang, W. Li, S. Lu, F. Tian, J. Shen, E. Holmström, and L. Vitos, Scr. Mater. 108, 44 (2015).

23. S. Huang, W. Li, X. Li, S. Schönecker, L. Bergqvist, E. Holmström, L.K. Varga, and L. Vitos, Mater. Des. 103, 71 (2016).

24. S. Huang, Á. Vida, D. Molnár, K. Kádas, L.K. Varga, E. Holmström, and L. Vitos, Appl. Phys. Lett. 107, 251906 (2015).

25. S. Huang, Á. Vida, W. Li, D. Molnár, S.K. Kwon, E. Holmström, B. Varga, L.K. Varga, and L. Vitos, Appl. Phys. Lett. 110, 241902 (2017).

26. V.L. Moruzzi, J.F. Janak, and K. Schwarz, Phys. Rev. B 37, 790 (1988).

27. R. Hill, Proc. Phys. Soc. Sect. A 65, 349 (1952).

28. Y. Zhang, Y.J. Zhou, J.P. Lin, G.L. Chen, and P.K. Liaw, Adv. Eng. Mater. 10, 534 (2008).

29. C.J. Tong, Y.L. Chen, J.W. Yeh, S.J. Lin, S.K. Chen, T.T. Shun, C.H. Tsau, and S.Y. Chang, Metall. Mater. Trans. A 36,881 (2005).

30. X.F. Wang, Y. Zhang, Y. Qiao, and G.L. Chen, Intermetallics 15, 357 (2007).

31. L. Liu, J.B. Zhu, L. Li, J.C. Li, and Q. Jiang, Mater. Des. 44, 223 (2013).

32. S. Praveen, B.S. Murty, and R.S. Kottada, Mater. Sci. Eng. A 534, 83 (2012).

33. S. Guo and C.T. Liu, Prog. Nat. Sci. Mater. Int. 21, 433 (2011).

34. K. Sato, L. Bergqvist, J. Kudrnovský, P.H. Dederichs, O. Eriksson, I. Turek, B. Sanyal, G. Bouzerar, H. KatayamaYoshida, V.A. Dinh, T. Fukushima, H. Kizaki, and R. Zeller, Rev. Mod. Phys. 82, 1633 (2010).

35. F. Körmann, D. Ma, D.D. Belyea, M.S. Lucas, C.W. Miller, B. Grabowski, and M.H.F. Sluiter, Appl. Phys. Lett. 107, 142404 (2015).

36. D.C. Wallace, Thermodynamics of Crystals (New York: Wiley, 1972).

37. D.G. Pettifor, Mater. Sci. Technol. 8, 345 (1992).

38. J.F. Nye, Physical Properties of Crystals: Their Representation by Tensors and Matrices (New York: Oxford University Press, 1985).

39. S. Huang, C.H. Zhang, R.Z. Li, J. Shen, and N.X. Chen, Intermetallics 51, 24 (2014).

40. X.Q. Chen, H.Y. Niu, D.Z. Li, and Y.Y. Li, Intermetallics 19, 1275 (2011).

41. S.F. Pugh, Philos. Mag. 45, 823 (1954).

42. G. Wang, S. Schönecker, S. Hertzman, Q.M. Hu, B. Johansson, S.K. Kwon, and L. Vitos, Phys. Rev. B 91, 224203 (2015).

43. K. Jin, S. Mu, K. An, W.D. Porter, G.D. Samolyuk, G.M. Stocks, and H. Bei, Mater. Des. 117, 185 (2017).

44. G. Laplanche, P. Gadaud, O. Horst, F. Otto, G. Eggeler, and E.P. George, J. Alloys Compd. 623, 348 (2015).

45. L. Vitos and B. Johansson, Phys. Rev. B 79, 024415 (2009). 